\title{
MORAL POR PROVISÃO OU PROVISÓRIA EM RENÉ DESCARTES
}

\section{MORAL FOR PROVISION OR PROVISIONAL IN RENÉ DESCARTES}

\author{
ANGELA GONÇALVES ${ }^{1}$ \\ (Pontificia Universidade Católica RS, Brasil)
}

\begin{abstract}
RESUMO
O presente artigo tem a finalidade de mostrar a gênese da moral cartesiana, em que consiste esta e qual o objetivo da mesma. Explica por que se defende uma moral por provisão e não provisória. Mostra o motivo pelo qual é necessário uma moral e por que não se pode ficar irresoluto enquanto se constrói os fundamentos da ciência. Justifica o motivo pelo qual o autor apresenta essa moral após os preceitos do método, por que ela faz parte do mesmo, a sua função e por que está nesta ordem. Também explica o espírito do método, da moral e a diferença entre ambos. Apesenta as quatro máximas desta moral, explicando cada uma e quais são seus tópicos principais. Mostra também a relação da moral com o conhecimento e por que esta traduz-se em sabedoria. Por fim, mostra os pontos de vista de autores em relação a esta moral, se é por provisão ou provisória. Esta moral é importante para Descartes enquanto ele constrói os fundamentos da ciência.
\end{abstract}

Palavas-chave: Moral. Provisão. Provisória. Máximas. Sabedoria.

\begin{abstract}
This article intends to show the origin of Cartesian moral, what its purpose and objective. It explains why the defence of the moral for provision and not provisional. It shows the reason why one needs a moral and why it can't remain irresolute while building the foundations of science. It's elucidates why the author presents this moral after the precepts of method, what its function is and why this moral is in this order. It also explains the spirit of the method, moral and the difference between them. It presents the four maxims of this moral, explaining each one and what their main topics. It also shows the relationship of moral with the knowledge and why this moral expresses sagacity. Finally, it shows points of views authors about if this moral is for provision or provisional. This moral is important for Descartes while he builds the fundaments of science.
\end{abstract}

Keywords: Moral. Provision. Provisional. Maxims. Sagacity.

Descartes sempre deixou traços, resquícios ou manifestações sobre a sua moral em geral. Para ele, na palavra sabedoria, estavam incluídas as ciências e, nestas, a moral.

Como manifestação genuína de sua moral, o autor escreveu dois textos em latim os quais não foram publicados por ele: Exercício da boa mente (Studium bonae mentis) e Reflexões privadas (Cogitationes privatae). Quem os publicou foi Baillet em seu livro intitulado Vida de senhor Descartes (Vie de Monsieur Descartes). Do primeiro livro, existem somente pequenos extratos de traduções. Este foi traduzido por Baillet de duas maneiras: por Étude de bon sens ou Art de bien comprendre (Estudo do bom senso e Arte de bem compreender) (BAILLET, 1946, p. 191). O escrito Bonae mentis (Sobre a boa mente) trata, em síntese de: “[...] considerações sobre o desejo que temos de saber sobre as ciências, sobre 
as disposições do espírito para aprender sobre a ordem que se deve manter para adquirir a sabedoria, isto é, a ciência com a virtude, unindo as funções da vontade com aquelas do entendimento" (BAILLET, 1946, p. 191).

Vejamos que é a primeira ideia de moral em seus escritos que traduz-se pela menção do nome virtude. Quer dizer, a sabedoria é a união da ciência com a virtude.

Descartes recebeu, no que concerne à moral, influência dos estoicos. Diz Cícero ao se expressar em relação à virtude: "Aperfeiçoar, como dizemos, a obra da natureza naquilo que há nela de melhor, que é a virtude. É nisto que consiste o principal mérito do homem" (CICÉRON, 1930, p. 37). O principal louvor do homem é a virtude.

E ainda para Sêneca:

\begin{abstract}
O sumo bem é uma alma que despreza os azares da sorte e alegra-se com a virtude [...]. O homem feliz é aquele para quem não há nem bem nem mal, mas uma alma boa ou má, que pratica o bem, contenta-se com a virtude [...]. O sumo bem é a concórdia da alma; pois as virtudes deverão estar onde existirem o consenso e a unidade (SENECA, 1862, p. 2-6).
\end{abstract}

Em ambos os autores estoicos, pode-se observar o entrelaçamento do louvor do homem, do sumo bem à virtude. É de vital importância a passagem de Sêneca ao dizer que: "as virtudes deverão estar onde existirem o consenso e a unidade" (SENECA, 1862, p. 2-6). Diz respeito ao que Descartes preconiza: a não pluralidade de opiniões e, sim, a unidade, a concordância, o conhecimento de uma única verdade, isso é igual a virtude que traduz-se em sabedoria, sumo bem.

Na obra de Descartes intitulada Regras para a Direção do Espírito, não há uma preocupação de o entendimento buscar somente um método; a ciência se identifica com a sabedoria, como esta passagem:

Pois, sendo dado que todas as ciências são a sabedoria humana, que permanece sempre uma e a mesma, tão diferentes que sejam os assuntos aos quais ela se aplique, e que não lhes tira nada, da mesma maneira que a luz do sol não o faz, em relação à variedade das coisas que ele ilumina; não é necessário impor aos espíritos nenhum limite. O conhecimento de uma única verdade, como o exercício de uma única arte, não nos impede de descobrir uma outra, mas nos ajuda sobretudo a fazêlo". (DESCARTES, 1953, p. 37-38).

Segundo Benes Alencar Sales, as ciências estão ligadas entre si, e é melhor apreendêlas na sua totalidade e não separar umas das outras. As pessoas devem aumentar a luz da razão para usá-la adequadamente nas diversas situações. A sabedoria não engloba somente a ciência, mas identifica-se com ela (SALES, 2013, p. 48-49). Existe uma preocupação do autor em relacionar a moral à ciência. 
Na terceira parte do Discurso do Método, o leitor encontra a "moral por provisão". Utiliza-se "moral por provisão", em primeiro lugar, porque no texto escrito pelo próprio Descartes está "eu constitui para mim uma moral por provisão" (DESCARTES, 1953, p. 140141); "por provisão" (ROBERT, 1980, p. 753), significa tempo, duração, e não provisória (provisoire). Em segundo lugar, provision (ROBERT, 1980, p. 867), significa provisão, isto é, abastecimento; tem também a acepção de prover-se de algo; munir-se. Isso significa que, antes de reconstruir a casa onde se mora, é importante prover-se de outra com um teto seguro para reconstruir os fundamentos da ciência. É uma necessidade ter-se um teto seguro para a constituição dessa moral. É no sentido de se ter um lugar seguro, prover-se nele que a moral se insere e não no sentido de provisoriedade. Descartes, em momento algum, deu a entender que a moral seria provisória. O que importa para um alojamento é que ele esteja em condições de se habitar, e que já tenha um teto. Se ele é provisório ou não, não importa. Alguns autores utilizam moral provisória em oposição a uma moral dita definitiva. Parece que o provisório será substituído pelo definitivo para eles.

O termo provisão é mais adequado para o sentido que o autor utiliza na obra a saber:

E enfim, como não basta, antes de começar a reconstruir a casa onde se mora, que derrubá-la e prover-se de materiais e arquitetos, ou exercer a si mesmo a arquitetura, nem, além disso, ter delineado cuidadosamente seu projeto, é necessário também terse provido de outra qualquer onde se possa morar comodamente durante o tempo em que nela se trabalhar; [...] (DESCARTES, 1953, p. 140).

"Ter-se provido de outra qualquer onde se possa morar comodamente durante o tempo em que nela se trabalhar", ou seja, enquanto se constroem os fundamentos das ciências, temse a necessidade de se prover de um teto ou abrigo durante esse tempo de reconstrução, durante a espera da construção dos fundamentos das ciências. Embora se possa fazer uma suspensão de juízos (no que concerne aos fundamentos das ciências), não se pode fazer uma interrupção nas ações. A moral objetiva a exoneração da irresolução no que tange às ações humanas. A moral por provisão faz-se necessária enquanto Descartes está envolvido no projeto da construção da ciência verdadeira. A provisoriedade que alguns autores denominam, não está relacionada à moral, mas à construção das ciências. Essa moral é consequência da não irresolução, isto é, não se pode ficar indeciso enquanto se está envolvido nesse projeto.

É relevante se questionar por que o autor apresenta esse capítulo após ter apresentado os preceitos de seu método. Será que a moral por provisão faz parte do método cartesiano?... Qual é o motivo pelo qual Descartes apresenta nessa ordem, isto é, após os preceitos? Acredita-se que ela é tirada do método como consequência do tempo que é necessário para a 
construção dos fundamentos das ciências vislumbrado por Descartes. E ainda é preciso ter-se um teto para morar. A moral por provisão tem uma função de extrema importância na etapa da construção das ciências, porque é condição necessária, intrínseca à aplicação do método. Ela está nesta ordem, porque é condição para a realização do caminho que foi sugerido pelo filósofo. É mister crer em alguma coisa, nas tradições, nas religiões, na cultura na qual se está inserida. Deve-se estar em contato com a sociedade, com outros homens sob determinadas leis e costumes, num certo país. Neste período, existe uma contradição radical entre não permanecer indeciso no que concerne às ações práticas, ao mesmo tempo em que a razão se obriga a ser irresoluta em seus juízos. Segundo Merkaert (MERKAERT, 1975, p. 613), num primeiro momento, a irresolução impede a ação, mas é uma etapa necessária ligada à dúvida. Saliente-se que há uma perfeita independência entre o plano de ação e o plano do pensamento, pelo menos nesta etapa da construção do sistema.

Pode-se questionar qual é o lugar da moral por provisão no sistema cartesiano. Acredita-se que ela se insere sistematicamente no conjunto da obra do autor. A moral foi tirada do método. Só que a constituição dessa moral tem um espírito diferente do espírito do método. O fundamento do método é a dúvida, tem que se suspender o juízo até chegar a uma ideia clara e distinta. $\mathrm{Na}$ moral, ao contrário, cumpre confiar nas autoridades, seguir as tradições. Na moral, não existe um rigor, mas sim o bom-senso.

São estabelecidas regras ou máximas com o objetivo de não ficar paralisado pela incerteza nos assuntos práticos, não filosóficos da vida (SKIRRY, 2010, p. 203). Apesar disso, tem de se viver o mais felizmente possível.

Por isso, Descartes apresenta quatro máximas às quais chama de moral por provisão.

A primeira é:

Obedecer às leis e aos costumes de meu país, retendo constantemente a religião em que Deus me concedeu a graça de ser instruído desde minha infância, e governandome, em todas as outras coisas, seguindo as opiniões mais moderadas e as mais distanciadas do excesso, que fossem comumente acolhidas em prática pelos mais sensatos daqueles com os quais teria de viver (DESCARTES, 1953, p. 141).

Apesar das incertezas das crenças anteriores, é melhor levar uma vida sensata e moderada. Para que isso aconteça, é melhor seguir diretrizes, ou seja, obedecer às leis, aos costumes de seu país e à religião. Seguir também as ações das pessoas mais sensatas e moderadas, faz juz a essa máxima. Isso significa que é mais provável que o agir das pessoas de bem seja mais correto do que ações extremas?... A pergunta tem de ser feita pela constatação de que existem ações insensatas. Geralmente, as pessoas falam coisas e agem do 
modo diferente na prática. Essas são ações imoderadas e insensatas. Portanto, uma pessoa moderada e sensata age e vive de acordo com elas. Isso quer dizer que a conduta revela a qualidade, a sinceridade, a eficácia das convicções. A moderação e a sensatez, no caso, podem ser consideradas maneiras para não se desviar do reto caminho, pois é mister para Descartes não se desviar do aperfeiçoamento cada vez mais dos seus juízos. O excesso é a radicalização do "meio caminho", ou seja, da moderação. É mais fácil não errar pela moderação e sensatez, a fim de não se desviar do verdadeiro caminho. A crença religiosa também, nesse período de dúvida, é um meio pelo qual pode-se apoiar, pode servir de guia para a conduta moral.

A segunda máxima diz respeito ao indivíduo ser firme em suas ações e não dar crédito a opiniões duvidosas:

Minha segunda máxima consiste em ser o mais firme e o mais resoluto possível em minhas ações, e em não seguir menos constantemente do que se fossem muito seguras as opiniões mais duvidosas; sempre que eu me tivesse decidido a tanto (DESCARTES, 1953, p. 142).

Ser irresoluto é um mal. A vida e em especial as ações excluem hesitações. Mesmo que não se tenha certeza de tal verdade, deve-se tomar a atitude mais provável. A segurança moral livra a consciência de arrependimento e de remorsos, fruto de irresoluções. Descartes diz que: "as consciências desses espíritos fracos e vacilantes que se deixam levar a praticar ações como boas, as coisas que depois julgam más" (DESCARTES, 1953, p. 142). Ficar parado ou perambular de um lado para o outro (como o exemplo do viajante) faz com que não se tenha, pelo menos, algum rumo ou orientação. É imperiosa a necessidade de, pelo menos, encontrar uma situação melhor ou um caminho mais provável. A firmeza nas ações é importante para se fazer algum progresso.

Dito isso, a terceira máxima refere-se ao controle de desejos: vencer a si próprio e controlar os próprios pensamentos. 
Minha terceira máxima era a de procurar sempre antes vencer a mim próprio do que à fortuna, e de tentar mudar antes os meus desejos do que a ordem do mundo; e, em geral, a de acostumar-me a crer que nada há que esteja inteiramente em nosso poder, a não ser nossos pensamentos, de sorte que, depois de termos feito o melhor possível no que concerne às coisas que nos são exteriores, tudo em que deixamos de nos sair bem é, em relação a nós, absolutamente impossível (DESCARTES, 1953, p. 142143).

O homem e, propriamente dito, seus pensamentos é que têm autonomia. Ele dirige-se a si mesmo, ele é que tem seu autocontrole. Aqui, Descartes enaltece o autocontrole racional, ou seja, eu é que comando os meus desejos, que é o segredo da felicidade. A força é interior, o que está em nosso poder são nossos pensamentos. Deve-se desejar apenas as coisas que estão em nosso poder alcançar e não aquilo que está além dele, porque existem coisas que não estão ao nosso alcance. Deve-se também abstrair à fortuna. Essa regra pressupõe uma disciplina de nossos poderes, porque nossos apetites e nossas paixões nos ditam justamente o contrário e atrapalham nossa paz interior nos fazendo desejar o impossível.

Para a conclusão dessa moral, Descartes cita como última máxima:

Enfim, para a conclusão dessa moral, eu resolvi passar em revista as diversas ocupações que os homens têm nesta vida, para empenhar-me em escolher a melhor; e, sem que eu deseje dizer nada sobre as dos outros, eu pensei que o melhor a fazer seria continuar naquela mesma em que me achava, isto é, empregar toda a minha vida em cultivar minha razão, e adiantar-me, o mais que pudesse, no conhecimento da verdade, seguindo o método que me prescrevera (DESCARTES, 1953, p. 143 144.).

Nesta última máxima o autor, depois de refletir sobre as ocupações, todos os trabalhos da vida, chega à conclusão de que a melhor ocupação é a dele, ou seja, ocupar-se em cultivar a razão e principalmente na busca da verdade. Ocupar-se com o método que prescrevera é a melhor ocupação. Descartes encontra-se satisfeito, honroso e feliz de seguir a sua vocação: a procura da verdade segundo a razão, isto é, a construção dos fundamentos da ciência. O bomsenso é que julgará se algo é bom ou ruim e temos de julgar o melhor possível para proceder também da melhor maneira.

Diante destas máximas, pode-se dizer que a moral por provisão seria uma etapa (não irresoluta), enquanto Descartes duvida de tudo (busca a verdade) dentro da ordem das ações (conduta) para tratar de descobrir o melhor possível ou mais razoável nas ações, procurando a felicidade ou viver o melhor possível, segundo a razão. Ela depende de nós mesmos, da melhor utilização do nosso livre arbítrio. Essa etapa é de suma importância para uma direção da moral também antes da reconstrução da ciência. Não é por acaso que Descartes escreve a 
moral por provisão, após ter escrito os preceitos do método. Ela tem uma função no método, e é condição necessária enquanto se elabora o modo de proceder. Pode-se também questionar o que tem a ver essa moral com o conhecimento. Exemplo disso é quando o autor apresenta a árvore do conhecimento. Na Carta-prefácio dos Princípios da Filosofia ao tradutor desse livro, diz que vai explicar a ordem que se deve seguir para obter instrução assim:

[...] deve-se começar bem a aplicar-se a verdadeira filosofia, cuja primeira parte é a metafísica, que contém os princípios do conhecimento, entre os quais a explicação dos principais atributos de Deus, da imaterialidade das nossas almas, e de todas as noções claras e simples que estão em nós. A segunda é a física em que, depois de se ter encontrado os verdadeiros princípios das coisas materiais, examina-se, na generalidade, como todo o universo é composto; depois, em particular, qual é a natureza desta terra e de todos os corpos que se encontram o mais comumente à sua volta, como o ar, a água, o fogo, o ímam e outros minerais. Em seguida, é então necessário também examinar,em particular, a natureza das plantas, aquela dos animais e, sobretudo, a do homem, a fim de que seja capaz de descobrir as outras ciências que lhe são úteis. Assim, toda a filosofia é como uma árvore, cujas raízes são a metafísica; o tronco é a física, e os ramos que saem deste tronco são todas as outras ciências que se reduzem a três principais: a medicina, a mecânica e a moral, eu entendo por moral a mais elevada e mais perfeita a que, pressupondo inteiro conhecimento das outras ciências, é o último grau de sabedoria (DESCARTES, 1953, p. 565-566.).

Por isso, presume-se que a moral seria uma ramificação das ciências, quando Descartes apresenta essa árvore. Isso traduz que "uma moral é deduzida de uma metafísica e de uma física completa" (SILVA, 1994, p. 88). Descartes diz que a moral "pressupõe um conhecimento integral das outras ciências, justamente porque 'a mais elevada e mais perfeita [moral] é o último grau da sabedoria” (DESCARTES, 1953, p. 566). A moral está relacionada ao conhecimento, quer dizer, às ciências. Por quê? Porque a moral traduz-se em sabedoria para Descartes, ela pressupõe um total conhecimento das outras ciências. Por isso vem, por último, na árvore do saber. A união das ciências com a virtude (moral) forma a sabedoria e essa é a perfeição da vida. Não se pode dissociar metafísica e moral, pois é eficaz para a maior perfeição do homem. Existe uma relação intríseca entre ciência e sabedoria.

Segundo Gueroult: "É ainda a ela que Descartes faz alusão quando ele concebe que a moral a mais perfeita 'pressupõe o conhecimento total das outras ciências [...]"(GUEROULT, 1968, p. 243).

No que concerne às interpretações sobre essa moral, existem diversas. Dentre os autores que interpretam a moral como moral provisória, Étienne Gilson (GILSON, 1967, p. 65) diz que a "moral definitiva" é possível e só não foi escrita por questões contingenciais à vida de Descartes. Segundo ele, algumas máximas como é o caso da terceira regra, a da 
firmeza das ações, Descartes "passará tal qual à moral definitiva". Já Lívio Teixeira (TEIXEIRA, 1990, p. 111-112) alega que Descartes jamais escreveu tal moral, dita definitiva, nem se quer pode-la-ia escrever, isso porque - entende aquele comentador - a lógica interna da metafísica cartesiana não o permitiria. Ainda segundo esse autor (TEIXEIRA, 1990, p. 111112), a moral de Descartes é racional, pois deve ser orientada pela razão ou inteligência.

Dentre os autores que concordam com a interpretação da moral como "moral por provisão", Rodis-Lewis explica que ela é "tirada do método" não como resultado das quatro regras da segunda parte, mas como uma necessidade para aplicá-las com rigor (RODILEWIS, 1988, p. 18). Ainda, Robert Spaemann diz que "a ênfase recai não sobre o caráter provisório, mas sobre o sentido do termo 'provision' (provisão) como 'approvisionnement' (conjunto de provisões) [...]”(SPAEMANN, 1972, p. 357). Continua Spaemann: “O importante para um alojamento, seja ele provisório ou não em oposição ao grande edifício que está ainda em construção, é que ele esteja completo e que já tenha um teto" (SPAEMANN, 1972, p. 357).

Concorda-se com esse autor, porquanto o importante é ter um teto, mas se ela é provisória ou não, isso não está importando no momento. O que é relevante é a constituição dessa moral enquanto se constroem os fundamentos da ciência.

Então, antes de habitar comodamente o edifício da ciência, faça-se uma provisão de regras para não permanecer indeciso no que diz respeito às ações. 


\section{Notas:}

${ }^{1}$ Mestre em Filosofia pelo Programa de pós-graduação em Filosofia da Pontifícia Universidade Católica do Rio Grande do Sul (PUCRS). E-mail: angelagoncalvesjolie@gmail.com. 


\section{Referências bibliográficas:}

DESCARTES, René. Discours de la méthode: troisième partie. In: DESCARTES, René. Euvres et lettres. Paris: Bibliothèque de La Pléiade, 1953.

. Les principes de la philosophie. In: DESCARTES, René. GEuvres et lettres. Paris: Bibliothèque de La Pléiade, 1953.

. Règles pour la direction de l'esprit: règle I. In: DESCARTES, René. Euvres et lettres. Paris: Bibliothèque de La Pléiade, 1953.

GUEROULT, Martial. Descartes selon l'ordre des raisons: I L'Ame et Dieu. Paris: AubierMontaigne, 1953.

MERKAERT, Norma. Les trois moments moraux du Discours de la méthode. Revue philosophique de Louvain, n. 73, 1975.

ROBERT, Micro. Dictionnaire du français primordial. Paris: Brodart et Taupin, 1980. Tome II.

RODIS-LEWIS, Geneviève. La Morale de Descartes. Paris: Presses Universitaires de France, 1988.

SALES, Benes Alencar. Descartes: das paixões à moral. São Paulo: Loyola, 2013.

SILVA, Franklin Leopoldo e. Descartes: a metafísica da modernidade. 3. ed. São Paulo: Moderna, 1994.

SKIRRY, Justin. Compreender Descartes. São Paulo: Vozes, 2010.

SPAEMANN, Robert. La morale provisoire de Descartes. Archives de Philosophie, Paris, n. $35,1972$.

TEIXEIRA, Lívio. Ensaio sobre a moral de Descartes. São Paulo: Secretaria de Estado da Cultura e Editora Brasiliense, 1990. 